\title{
Acute Toxicity and Ecological Risk Assessment of Benzophenone and $N, N$-Diethyl-3 Methylbenzamide in Personal Care Products
}

\author{
Hong-Qin Sun ${ }^{1,2}$, Yang Du ${ }^{1}$, Zi-Yang Zhang ${ }^{3}$, Wen-Jing Jiang ${ }^{1}$, Yan-Min Guo ${ }^{1}$, Xi-Wu Lu ${ }^{1,2}$, \\ Yi-Min Zhang ${ }^{4, *}$ and Li-Wei Sun ${ }^{1,2, *}$ \\ 1 School of Energy and Environment, Southeast University, 2 Sipailou, Nanjing 210096, China; \\ sunhongqin123456@163.com (H.-Q.S.);ngd2011dy@126.com (Y.D.); 2010jwj@sina.com (W.-J.J.); \\ 220140548@seu.edu.cn (Y.-M.G.); xiwulu@seu.edu.cn (X.-W.L.) \\ 2 Taihu Lake Water Environment Engineering Research Center (Wuxi), Southeast University, 99 Linghu Street, \\ Wuxi 214000, China \\ 3 Department of Building, Civil, and Environmental Engineering, Concordia University, \\ 1455 de Maisonneuve, Boulevard West, Montreal, QC H3G 1M8, Canada; zhangziyang1028@hotmail.com \\ 4 Research Center of Watershed Ecological Conservation and Water Pollution Control, \\ Nanjing Institute of Environmental Sciences, Ministry of Environmental Protection of the People's Republic \\ of China, 8 Jiangwangmiao Street, Nanjing 210042, China \\ * Correspondence: zym@nies.org (Y.-M.Z.); liwei-sun@seu.edu.cn (L.-W.S.); \\ Tel.: +86-153-6609-0985 (Y.-M.Z.); +86-150-7786-1046 (L.-W.S.)
}

Academic Editor: Paul Tchounwou

Received: 30 June 2016; Accepted: 1 September 2016; Published: 19 September 2016

\begin{abstract}
Benzophenone (BP) and N,N-diethyl-3-methylbenzamide (DEET) are two chemicals often used in personal care products (PCPs). There is a lack of systematic ecotoxicological evaluations about the two chemicals to aquatic organisms. In the present study, the acute toxic effects on Chlorella vulgaris, Daphnia Magana, and Brachydanio rerio were tested and the ecotoxicological risks were evaluated. For BP, the 96-h half-maximal effective concentration $\left(\mathrm{EC}_{50}\right)$ on $\mathrm{C}$. vulgaris was $6.86 \mathrm{mg} / \mathrm{L}$; the $24-\mathrm{h}$ median lethal concentration $\left(\mathrm{LC}_{50}\right)$ on D. magana was $7.63 \mathrm{mg} / \mathrm{L}$; the $96-\mathrm{h}_{50}$ on B. rerio was $14.73 \mathrm{mg} / \mathrm{L}$. For DEET, those were $270.72 \mathrm{mg} / \mathrm{L}, 40.74 \mathrm{mg} / \mathrm{L}$, and $109.67 \mathrm{mg} / \mathrm{L}$, respectively. The mixture toxicity of $\mathrm{BP}$ and DEET, on C. vulgaris, D. magana, and B. rerio all showed an additive effect. The induced predicted no-effect concentrations (PNECs) for BP and DEET by assessment factor (AF) method are $0.003 \mathrm{mg} / \mathrm{L}$ and $0.407 \mathrm{mg} / \mathrm{L}$, respectively. Both are lower than the concentrations detected from environment at present, verifying that BP and DEET are low-risk chemicals to the environment.
\end{abstract}

Keywords: benzophenone; $\mathrm{N}, \mathrm{N}$-diethyl-3-methylbenzamide; personal care products; acute toxicity; ecological risk assessment

\section{Introduction}

Personal care products (PCPs) are one of the groups in emerging pollutants and are integral to people's activities of daily life. Pedrouzo et al. [1] sub-classified PCPs into six categories: organic ultraviolet (UV) filters, antimicrobials, preservatives, musk fragrances, insect repellents, and siloxanes. These compounds are not usually considered in routine environmental monitoring, but are becoming of environmental concern because of their increasingly common use and the potential risk to human and ecosystem health. With the improvement in detection techniques, an increasing number of PCPs are being detected from different aquatic environments [2]. A study [3] also indicated that 2-Hydroxy-4-methoxybenzophenone (BP-3), one ingredient of PCPs, has been detected from the 
human body. Furthermore, the concentrations of BP-3 in females are higher than those in males, because females tend to use cosmetics more than males do. The result indicated that the risk of exposure to PCPs is related to human lifestyles. Predictably, with changes in lifestyles, the types and amounts of PCPs being used will gradually increase; therefore, the evaluations about the ecological risk and hazardous impact on human health of PCPs should be emphasized.

Benzophenone (BP) is a main member of UV filters, and is extensively used as a sunscreen agent [4] to protect skin and hair [5] from being damaged by UV rays. BP is also used in perfumes, as it can provide a sweet smell [6]. BP has been detected in various aquatic environments, including surface water, sediment [7], and urban sewage. BP can generally enter the body through breathing, diet, and skin contact. Toxicological studies [8] have shown that BP is regarded as the third-generation environmental pollutant (endocrine disruptors) because of its genetic toxicity and biological toxicity effects. However, research $[5,9]$ on ecological toxic effects of BP remains scarce.

Diethyltoluamide ( $N, N$-diethyl-3-methylbenzamide or DEET) is the main ingredient of insect repellents. DEET has been used as an insect repellent for a long time, and its consumption is very high. DEET has been detected in different aquatic environments [10], but there few ecological toxicity studies [11] on DEET have been reported.

To evaluate the ecological toxicity of BP and DEET, Chlorella vulgaris, Daphnia magna, and Brachydanio rerio were employed to conduct independent acute toxicity and further mixed toxicity tests. The three organisms used in the toxic test are representative ones for the 3 typical tropic levels in the aquatic ecosystem: $C$. vulgaris represented the autotrophs (primary producer); $D$. magna represented the primary consumer (predator); B. rerio represented the second consumer (second predator).

All the experiments were conducted in accordance with Chinese National Standards: GB/T 21805-2008 (algae) [12], GB/T 16125-2012 (daphnia magna straus) [13], GB/T 27861-2011 (fish) [14]; and also methods in Analytical Methods for Water and Wastewater [15]. These methods basically referred to the OECD or ISO standards, except $C$. vulgaris is added as an algae candidate by the Chinese National Standards.

Based on the results of acute toxicity to the three organisms, the mixed toxicity of the two chemicals were tested, and then the ecological risk of BP and DEET were assessed by the predicted no-effect concentration (PNEC) - the maximum concentration at which the ecosystem is protected. The results will provide the scientific basis and reference value for formulating environmental criteria.

\section{Materials and Methods}

\subsection{Preparation of Chemicals}

Analytical purity grade BP was purchased from Sinopharm Chemical Reagent Co. Ltd. (Shanghai, China). DEET at 99\% purity was purchased from Aladdin Industrial Corporation (Shanghai, China). Analytical purity grade dimethyl sulfoxide was purchased from Sinopharm Chemical Reagent Co. Ltd. and used as a cosolvent.

\subsection{Experimental Biota for Toxicity Test}

C. vulgaris (FACHB-8) was obtained from the Freshwater Algae Culture Collection, at the Institute of Hydrobiology, Chinese Academy of Sciences (Wuhan, China). The algae were cultured for three generations in the laboratory before the toxicity experiments. The algae cells in the logarithmic growth phase were used for toxicity experiments. The experiments were conducted in an illumination incubator to maintain the same condition: 2000-3000 lx, $25 \pm 2{ }^{\circ} \mathrm{C}, \mathrm{pH} 7.1,12 \mathrm{~h}: 12 \mathrm{~h}$ light-dark cycle.

D. magna were obtained from the Freshwater Algae Culture Collection at the Institute of Hydrobiology, Chinese Academy of Sciences (Wuhan, China). The D. magna were cultured in the laboratory and were tested by potassium dichromate before the toxicity experiments. The D. magna for the test were 6-24-h old. The experiments were conducted using an illumination incubator to maintain the same condition: $25 \pm 2{ }^{\circ} \mathrm{C}, \mathrm{pH}$ 7.0-8.0, $12 \mathrm{~h}: 12 \mathrm{~h}$ light-dark cycle. 
B. rerio (AB strains) were ordered from Nanjing YSY Biotech Company Ltd. (Nanjing, China). The average body length was $2.60 \pm 0.20 \mathrm{~cm}$, average body weight was $0.33 \pm 0.06 \mathrm{~g}$, and potassium dichromate was used to test the sensitivity of $B$. rerio before the toxicity experiments. The experiments were carried out at: $25 \pm 2{ }^{\circ} \mathrm{C}, \mathrm{pH} 7.0-8.0,12 \mathrm{~h}: 12 \mathrm{~h}$ light-dark cycle.

\subsection{Experimental Design}

\subsubsection{Ninety-Six Hours Acute Toxicity Experiments with C. vulgaris}

During the acute toxicity experiments on C. vulgaris, BG 11 liquid medium and BP or DEET stock solution were used to prepare a serial concentration of solution $(100 \mathrm{~mL})$ in a glass flask $(250 \mathrm{~mL})$. The initial density of C. vulgaris was $10^{6}$ cells $/ \mathrm{mL}$, and the experiment lasted $96 \mathrm{~h}$. Each concentration test, including cosolvent and blank control groups, was designed with three parallel samples. Before the experiment, microscopic counting and spectrophotometry were employed to obtain the linear correlation between the $C$. vulgaris cells density and absorbance at $680-\mathrm{nm}$ wavelength. During the period of the experiment, the absorbance of $C$. vulgaris was measured every $24 \mathrm{~h}$, then it was converted to cell density to calculate growth rates.

\subsubsection{Twenty-Four Hours Acute Toxicity Experiments with D. magna}

Aerated tap water was used to prepare a serial concentration of BP or DEET solution. Ten D. Magna were put in a 100-mL glass beaker with $80 \mathrm{~mL}$ of solution. The experiments lasted $24 \mathrm{~h}$. Each concentration test including cosolvent and blank control groups were designed with three parallel samples. The numbers of the dead individuals were recorded at the end of the test.

\subsubsection{Ninety-Six Hours Acute Toxicity Experiments with B. rerio}

Aerated tap water was used to prepare a serial concentration of BP or DEET solution. Ten fish were put in a $5000-\mathrm{mL}$ glass beaker with $4000 \mathrm{~mL}$ of solution. The experiments lasted $96 \mathrm{~h}$. Each concentration test including cosolvent and blank control groups were designed with three parallel samples. The numbers of the dead individuals were recorded every $24 \mathrm{~h}$.

\subsubsection{The Mixed Toxicity Experiment}

The mixed toxicity experiments of BP and DEET were performed in the same method as the independent toxicity experiments. The ratios of BP and DEET used for C. vulgaris, D. magna, and B. rerio were different. All ratios of $\mathrm{BP}$ and DEET were randomly prepared, referred to the obtained $\mathrm{EC}_{50}$ or $\mathrm{LC}_{50}$ values of each independent chemical, in order to imitate different conditions in the water.

Stock solutions were prepared for C. vulgaris $(7.50 \mathrm{mg} / \mathrm{L}$ BPand $276.65 \mathrm{mg} / \mathrm{L}$ DEET), D. magna (50.10 mg/L BP and $347.20 \mathrm{mg} / \mathrm{L}$ DEET), and B. rerio (50.10 mg/L BP and $690.30 \mathrm{mg} / \mathrm{L}$ DEET). All stock solutions were set up as $100 \%$; then, a series of solutions at different percentages were made for the test. When the $\mathrm{EC}_{50}$ or $\mathrm{LC}_{50}$ results are obtained as a percentage, the toxic units (TU) of BP and DEET can be calculated, respectively, by the following:

$$
\mathrm{TU}_{i}=\frac{C i}{E C 50 i},
$$

where $\mathrm{C}_{i}$ was the concentration of $i$ in the testing solution at the $\mathrm{EC}_{50}$ of the mixture.

$\mathrm{TUi}$ of BP + the TUi of DEET = the total TU of the mixture. If the total TU value at the endpoint of the mixture equaled 1 , the toxicity was assumed to be additive; if the total TU value at the endpoint of the mixture was $>1$, the toxicity was assumed to have an antagonistic effect; if the total TU value at the endpoint of the mixture was $<1$, the toxicity was deemed to have a synergistic effect. 


\subsection{Statistical Analysis}

OriginPro 9 software (OriginLab, Northampton, MA, USA) is used to draw graphs depicting the experimental results. IBM SPSS version 20 software (IBM, Armonk, NY, USA) was applied to calculate the 96-h half-maximal effective concentration $\left(\mathrm{EC}_{50}\right)$ of $C$. vulgaris, the 24-h median lethal concentration $\left(\mathrm{LC}_{50}\right)$ of D. magna, and $96-\mathrm{h} \mathrm{LC}_{50}$ of B. rerio.

\subsection{Ecological Risk Assessment}

AIST-MeRAM (National institute of Advanced Industrial Science and Technology-Multi-Purpose Ecological Risk Assessment and Management Tool, Japan, English ver. URL: http:/ / en-meram.aistriss.jp/) was employed to assess the ecological risk of the two chemicals. Two methods-assessment factor (AF) and species sensitivity distribution (SSD)—-were used to deduce the predicted no-effect concentration (PNEC).

\section{Results}

There was no significant difference between the dimethyl sulfoxide control group at the highest concentration and the blank control group for $C$. vulgaris growth rate, D. magna lethal rate, and B. rerio lethal rate by analysis of variance. This indicated that dimethyl sulfoxide had no repression effect on C. vulgaris, D. magna, and B. rerio in this study. All the results were analyzed by comparing the testing to the blank control groups.

In the present study, the chemical concentrations were set up based on the results of the pre-test, so the concentration ranges are narrow and have good linear relation to the inhibition or mortality rates.

\subsection{Acute Toxicity of $B P$}

\subsubsection{C. vulgaris Growth Inhibition Test of BP}

The inhibition effect on C. vulgaris growth increased with the increasing in the concentrations. During the exposure time, although the algal growth rate was inhibited, the algal densities still showed an increasing trend. When the BP concentration was $10.00 \mathrm{mg} / \mathrm{L}$, there was almost no growth between 48 and $72 \mathrm{~h}$, but rapid growth from 72 to $96 \mathrm{~h}$.

The growth inhibition by BP concentration is shown in Figure 1A. The linear regression equation between $\mathrm{BP}$ concentration and its inhibition ratio was

$$
\mathbf{y}=-\mathbf{1 0 . 2 1 6}+\mathbf{8 . 9 7 9 x},(\mathrm{x}: 2.00 \mathrm{mg} / \mathrm{L} \sim 10.00 \mathrm{mg} / \mathrm{L}),
$$

where $\mathrm{x}$ is the $\mathrm{BP}$ concentration, and $\mathrm{y}$ is the inhibition ratio on $\mathrm{C}$. vulgaris growth (\%).

Using SPSS version 20 software, the $96-\mathrm{h} \mathrm{EC}_{50}$ was calculated as $6.86 \mathrm{mg} / \mathrm{L}$ ( $95 \%$ confidence interval: $6.40-7.34 \mathrm{mg} / \mathrm{L}$ ). This value was classified as high-level toxicity on C. vulgaris [15].
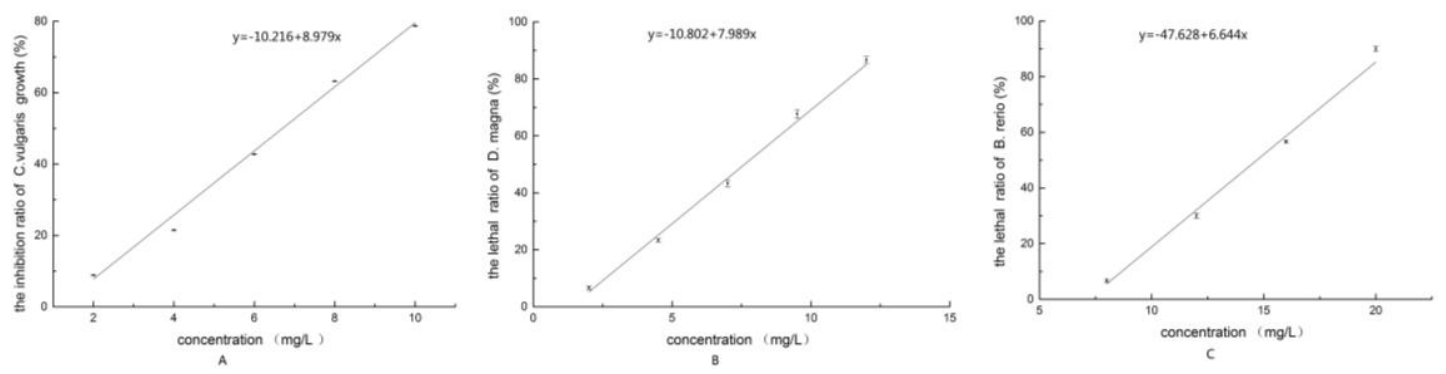

Figure 1. (A) The inhibition ratio of C. vulgaris growth of BP; (B) The lethal ratio of D. magna of BP; (C) The lethal ratio of B. rerio of BP. 


\subsubsection{Acute Toxicity of BP to D. magna}

When the concentrations range from 2.00 to $12.00 \mathrm{mg} / \mathrm{L}$, the relationship between the mortality of D. magna and BP concentration was described by a linear equation:

$$
\mathrm{y}=-10.802+7.989 x,(\mathrm{x}: 2.00 \mathrm{mg} / \mathrm{L} \sim 12.00 \mathrm{mg} / \mathrm{L}),
$$

where $\mathrm{x}$ is the $\mathrm{BP}$ concentration, and $\mathrm{y}$ is the mortality of D. magna (\%).

The 24-h LC 50 of D. magna for BP was $7.63 \mathrm{mg} / \mathrm{L}$ (95\% confidence interval: $7.13-8.14 \mathrm{mg} / \mathrm{L}$ ), the value was also classified as high-level toxicity [15]. The acute toxicity of $\mathrm{BP}$ to $D$. magna is shown in Figure 1B.

\subsubsection{Acute Toxicity of BP to B. rerio}

In a concentration range from 8.00 to $20.00 \mathrm{mg} / \mathrm{L}$, the relationship between the mortality of B. rerio and $\mathrm{BP}$ concentration was described by a linear equation:

$$
\mathrm{y}=-47.628+6.644 \mathrm{x},(\mathrm{x}: 8.00 \mathrm{mg} / \mathrm{L} \sim 20.00 \mathrm{mg} / \mathrm{L}),
$$

where $\mathrm{x}$ is the $\mathrm{BP}$ concentration, and $\mathrm{y}$ is the mortality of B. rerio (\%).

The acute toxicity of BP to B. rerio is shown in Figure $1 C$. The $96-\mathrm{h} \mathrm{LC}_{50}$ of B. rerio for BP was $14.73 \mathrm{mg} / \mathrm{L}$ (95\% confidence interval: $14.11-15.39 \mathrm{mg} / \mathrm{L}$ ), and this value was classified as medium-level toxicity [15].

\subsection{Acute Toxicity of DEET}

\subsubsection{C. vulgaris Growth Inhibition Test of DEET}

When the concentrations of DEET were between 79.04 and $395.20 \mathrm{mg} / \mathrm{L}$, there was an obvious inhibition effect on C. vulgaris. With the increasing in the concentrations, the inhibition effect also increased. The $C$. vulgaris growth inhibition ratio by DEET concentration is shown in Figure 2A. The linear regression equation used was as follows:

$$
\mathrm{y}=-4.459+0.202 \mathrm{x},(\mathrm{x}: 79.04 \mathrm{mg} / \mathrm{L} \sim 395.20 \mathrm{mg} / \mathrm{L}),
$$

where $\mathrm{x}$ is the DEET concentration, and $\mathrm{y}$ is the inhibition ratio on C. vulgaris (\%).
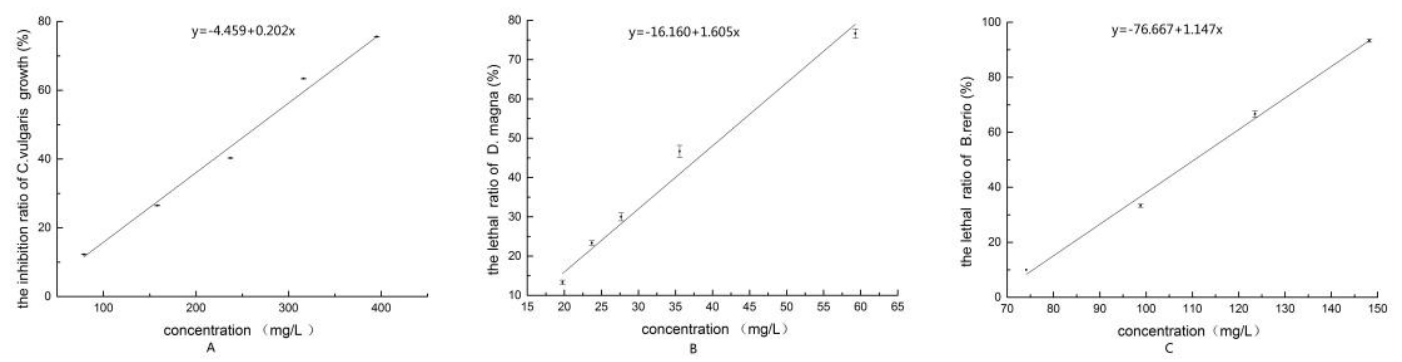

Figure 2. (A) The inhibition ratio of $C$. vulgaris growth of DEET; (B) The lethal ratio of D. magna of DEET; (C) The lethal ratio of B. rerio of DEET.

The $96-\mathrm{h} \mathrm{EC}_{50}$ was calculated as $270.72 \mathrm{mg} / \mathrm{L}$ (95\% confidence interval: $250.40-292.50 \mathrm{mg} / \mathrm{L}$ ) and showed low-level toxicity on C. vulgaris [15]. 


\subsubsection{Acute Toxicity of DEET to D. magna}

The mortality of $D$. magna by DEET concentration was described by a linear equation:

$$
\mathrm{y}=-16.160+1.605 \mathrm{x},(\mathrm{x}: 19.76 \mathrm{mg} / \mathrm{L} \sim 59.28 \mathrm{mg} / \mathrm{L}),
$$

where $\mathrm{x}$ is the DEET concentration, and $\mathrm{y}$ is the mortality to D. magna (\%).

The $24-\mathrm{h} \mathrm{LC}$ L $_{50}$ for DEET was $40.74 \mathrm{mg} / \mathrm{L}$ ( $95 \%$ confidence interval: $37.86-44.25 \mathrm{mg} / \mathrm{L}$ ), classified as medium-level toxicity [15]. The acute toxicity to D. magna of DEET is shown in Figure 2B.

\subsubsection{Acute Toxicity of DEET to B. rerio}

The mortality of B. rerio by DEET concentration was described by a linear equation:

$$
\mathrm{y}=-76.667+1.147 \mathrm{x},(\mathrm{x}: 49.40 \mathrm{mg} / \mathrm{L} \sim 148.20 \mathrm{mg} / \mathrm{L}),
$$

where $\mathrm{x}$ is the DEET concentration, and $\mathrm{y}$ is the mortality to B. rerio (\%).

The acute toxicity to B. rerio of DEET is shown in Figure 2C. The 96-h $\mathrm{LC}_{50}$ of DEET was $109.67 \mathrm{mg} / \mathrm{L}$ (95\% confidence interval: $106.14-141.15 \mathrm{mg} / \mathrm{L}$ ) and was classified as low-level toxicity [15].

\subsection{Mixed Acute Toxicity of BP and DEET}

\subsubsection{Acute Toxicity of the Mixture to C. vulgaris}

Based on the $\mathrm{EC}_{50}$ values of the independent toxicity experiments, the concentration of the mixture was calculated as a percentage of the total concentration (\%). The relationship between the concentration of the mixture and the growth inhibition ratio of $C$. vulgaris is shown in Figure 3A. There was a good linear relationship between the concentration of the mixture and the growth inhibition ratio of $C$. vulgaris. The $96-\mathrm{h} \mathrm{EC}_{50}$ of the mixture of BP and DEET on C. vulgaris was $46.31 \%$ (95\% confidence interval: $42.04 \%-51.21 \%$ ). In this case, the concentration of BP in the mixture was $3.43 \mathrm{mg} / \mathrm{L}$, and the concentration of DEET was $128.44 \mathrm{mg} / \mathrm{L}$. By calculating the TU values of BP and DEET using Equation (1), respectively, the total TU value at this point of the mixture equaled 1. Therefore, the toxicity of BP plus DEET combination showed an additive effect [16].
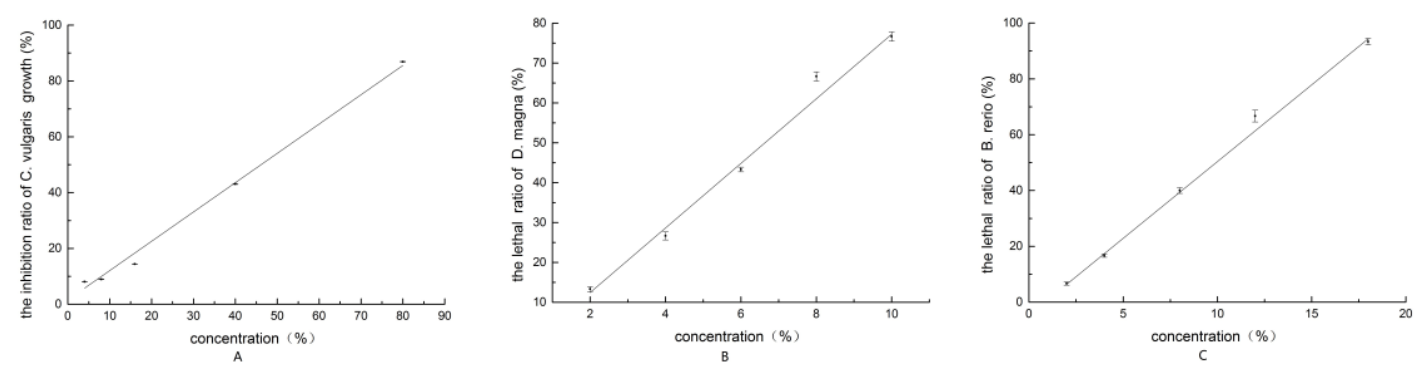

Figure 3. (A) The inhibition ratio of $C$. vulgaris growth by mixture; (B) The lethal ratio of $D$. magna by mixture; (C) The lethal ratio of B. rerio by mixture.

\subsubsection{Acute Toxicity of the Mixture to D. magna}

The mortality increased with the increasing in the concentration of mixture and showed a dose-response relationship. The acute toxicity of the mixture to D. magna is shown in Figure 3B.

The 24-h LC 50 of the mixture of BP and DEET to D. magna was $6.61 \%$ (95\% confidence interval: $6.11 \%-7.15 \%$ ), the concentration of BP in the mixture was $3.31 \mathrm{mg} / \mathrm{L}$, and the concentration of DEET was $22.95 \mathrm{mg} / \mathrm{L}$. The total TU value at this point of the mixture equaled 1, so the BP plus DEET combination showed an additive effect [16]. 


\subsubsection{Acute Toxicity of the Mixture to B. rerio}

The acute toxicity of the mixture to B. rerio is shown in Figure 3C. The mortality increased with the increasing in the concentrations and showed a dose-response relationship.

The $96-\mathrm{h} \mathrm{LC}_{50}$ of the mixture of BP and DEET to B. rerio was $9.59 \%$ (95\% confidence interval: $8.87 \%-10.36 \%$ ), the concentration of BP in the mixture was $4.80 \mathrm{mg} / \mathrm{L}$, and the concentration of DEET was $66.20 \mathrm{mg} / \mathrm{L}$. The total TU value at this point of the mixture equaled 1, so the BP plus DEET combination showed an additive effect [16].

\subsection{Assessment of the Acute Toxicity of BP and DEET}

Two methods- the AF method and the SSD method-were used to deduce the PNEC values in the present study. The AF method uses the lowest toxicity data of fish, crustaceans including daphnids, and algae to characterize risk as a margin of exposure (MOE). This is a point risk estimate model for screening or initial risk assessment. The AF is divided by an uncertainty factor (UF) to deduce the PNEC value. The UF is different in different countries and organizations. In this study, the UF was selected as 100, which is recommended by the OECD.

The SSD method uses all of the available toxicity data to describe the differences in species sensitivity to chemicals as a statistical distribution. The HC5 (the concentration at which $5 \%$ of the species are affected) is derived from the dose-response curve of species sensitivity distribution. This is a quantitative and probabilistic risk estimate model.

In the present study, UF was suggested as 5 by the producer of the RAM-MeAIST, and the log-normal distribution (LND) estimation method was selected in the assessing results.

\subsubsection{Assessment of the Ecotoxicological Effect of BP}

The values of 96-h $\mathrm{EC}_{50}$ of $C$. vulgaris, the 24-h $\mathrm{LC}_{50}$ of D. magna, and $96-\mathrm{h} \mathrm{LC}_{50}$ of $B$. rerio were applied to AIST-MeRAM. The deduced PNEC value by the AF method was $0.003 \mathrm{mg} / \mathrm{L}$ (using the uncertainty factor as 100), and was $0.480 \mathrm{mg} / \mathrm{L}$ by SSD (using the uncertainty factor as 5). The results including the former registered data are summarized in Table 1.

\subsubsection{Assessment of the Ecotoxicological Effect of DEET}

The values of the 96-h $\mathrm{EC}_{50}$ of $C$. vulgaris, the 24-h $\mathrm{LC}_{50}$ of $D$. magna, and $96-\mathrm{h} \mathrm{LC}_{50}$ of B. rerio were applied to AIST-MeRAM. The deduced PNEC value by the AF method was $0.407 \mathrm{mg} / \mathrm{L}$ (using the uncertainty factor as 100) and was $8.494 \mathrm{mg} / \mathrm{L}$ by the SSD method (using the uncertainty factor as 5). The results, including the former studies, are given in Table 2. 
Table 1. Acute toxicity result of benzophenone (including the former data registered in AIST-MeRAM).

\begin{tabular}{|c|c|c|c|c|c|c|}
\hline Endpoint & $\begin{array}{c}\text { Concentration } \\
(\mathrm{mg} / \mathrm{L})\end{array}$ & $\begin{array}{c}\text { Exposure Duration } \\
\text { (Days) }\end{array}$ & Species & Trophic Level & Source & Reference Number \\
\hline $\mathrm{EC}_{50}$ & 3.50 & 3 & $\begin{array}{c}\text { Unicellular green algae } \\
\text { (Pseudokirchneriella subcapitata) }\end{array}$ & Algae & $\begin{array}{l}\text { Ministry of the } \\
\text { Environment, Japan }\end{array}$ & 323 \\
\hline $\mathrm{LC}_{50}$ & 7.60 & 1 & Ceriodaphnia dubia & Daphnids & ECOTOX & 20160 \\
\hline $\mathrm{EC}_{50}$ & 0.28 & 1 & Daphnia magna & Daphnids & ECOTOX & 146689 \\
\hline $\mathrm{EC}_{50}$ & 10.00 & 2 & Daphnia magna & Daphnids & $\begin{array}{l}\text { Ministry of the } \\
\text { Environment, Japan }\end{array}$ & 323 \\
\hline $\mathrm{LC}_{50}$ & 7.63 & 1 & Daphnia magna & Daphnids & This study & \\
\hline $\mathrm{LC}_{50}$ & 15.30 & 4 & Fathead minnow (Pimephales promelas) & Fish & EPA FHM & 362 \\
\hline $\mathrm{EC}_{50}$ & 15.30 & 4 & Fathead Minnow (Pimephales promelas) & Fish & EAT & 5511 \\
\hline $\mathrm{LC}_{50}$ & 10.00 & 4 & Oryzias latipes & Fish & $\begin{array}{l}\text { Ministry of the } \\
\text { Environment, Japan }\end{array}$ & 323 \\
\hline $\mathrm{EC}_{50}$ & 13.70 & 1 & Pimephales promelas & Fish & ECOTOX & 23834 \\
\hline $\mathrm{EC}_{50}$ & 14.50 & 2 & Pimephales promelas & Fish & ECOTOX & 23835 \\
\hline $\mathrm{EC}_{50}$ & 15.20 & 2 & Pimephales promelas & Fish & ECOTOX & 23807 \\
\hline $\mathrm{LC}_{50}$ & 14.20 & 4 & Pimephales promelas & Fish & ECOTOX & 116411 \\
\hline $\mathrm{LC}_{50}$ & 14.20 & 4 & Pimephales promelas & Fish & ECOTOX & 102620 \\
\hline $\mathrm{LC}_{50}$ & 14.50 & 2 & Pimephales promelas & Fish & ECOTOX & 23809 \\
\hline $\mathrm{LC}_{50}$ & 14.80 & 1 & Pimephales promelas & Fish & ECOTOX & 23808 \\
\hline $\mathrm{LC}_{50}$ & 15.20 & 1 & Pimephales promelas & Fish & ECOTOX & 51866 \\
\hline $\mathrm{LC}_{50}$ & 15.20 & 2 & Pimephales promelas & Fish & ECOTOX & 23805 \\
\hline $\mathrm{LC}_{50}$ & 15.30 & 4 & Pimephales promelas & Fish & ECOTOX & 102597 \\
\hline $\mathrm{LC}_{50}$ & 14.73 & 4 & Brachydanio rerio & Fish & This study & \\
\hline
\end{tabular}


Table 2. Acute toxicity result of N,N-Diethyl-3-methylbenzamide (including the former data registered in AIST-MeRAM).

\begin{tabular}{|c|c|c|c|c|c|c|}
\hline Endpoint & $\begin{array}{c}\text { Concentration } \\
(\mathrm{mg} / \mathrm{L})\end{array}$ & $\begin{array}{c}\text { Exposure Duration } \\
\text { (Days) }\end{array}$ & Species & Trophic Level & Source & Reference Number \\
\hline $\mathrm{EC}_{50}$ & 3.50 & 3 & $\begin{array}{c}\text { Unicellular green algae } \\
\text { (Pseudokirchneriella subcapitata) }\end{array}$ & Algae & $\begin{array}{c}\text { Ministry of the } \\
\text { Environment, Japan }\end{array}$ & 323 \\
\hline $\mathrm{EC}_{50}$ & 6.86 & 4 & Chlorella vulgaris & Algae & This study & \\
\hline $\mathrm{LC}_{50}$ & 7.60 & 1 & Ceriodaphnia dubia & Daphnids & ECOTOX & 20160 \\
\hline $\mathrm{EC}_{50}$ & 0.28 & 1 & Daphnia magna & Daphnids & ECOTOX & 146689 \\
\hline $\mathrm{EC}_{50}$ & 10.00 & 2 & Daphnia magna & Daphnids & $\begin{array}{l}\text { Ministry of the } \\
\text { Environment, Japan }\end{array}$ & 323 \\
\hline $\mathrm{LC}_{50}$ & 7.63 & 1 & Daphnia magna & Daphnids & This study & \\
\hline $\mathrm{LC}_{50}$ & 15.30 & 4 & Fathead minnow (Pimephales promelas) & Fish & EPA FHM & 362 \\
\hline $\mathrm{EC}_{50}$ & 15.30 & 4 & Fathead Minnow (Pimephales promelas) & Fish & EAT & 5511 \\
\hline $\mathrm{LC}_{50}$ & 10.00 & 4 & Oryzias latipes & Fish & $\begin{array}{l}\text { Ministry of the } \\
\text { Environment, Japan }\end{array}$ & 323 \\
\hline $\mathrm{EC}_{50}$ & 13.70 & 1 & Pimephales promelas & Fish & ECOTOX & 23834 \\
\hline $\mathrm{EC}_{50}$ & 14.50 & 2 & Pimephales promelas & Fish & ECOTOX & 23835 \\
\hline $\mathrm{EC}_{50}$ & 14.90 & 1 & Pimephales promelas & Fish & ECOTOX & 23806 \\
\hline $\mathrm{EC}_{50}$ & 15.20 & 2 & Pimephales promelas & Fish & ECOTOX & 23807 \\
\hline $\mathrm{LC}_{50}$ & 14.20 & 4 & Pimephales promelas & Fish & ECOTOX & 116411 \\
\hline $\mathrm{LC}_{50}$ & 14.20 & 4 & Pimephales promelas & Fish & ECOTOX & 102620 \\
\hline $\mathrm{LC}_{50}$ & 14.50 & 2 & Pimephales promelas & Fish & ECOTOX & 23809 \\
\hline $\mathrm{LC}_{50}$ & 14.80 & 1 & Pimephales promelas & Fish & ECOTOX & 23808 \\
\hline $\mathrm{LC}_{50}$ & 15.20 & 1 & Pimephales promelas & Fish & ECOTOX & 51866 \\
\hline $\mathrm{LC}_{50}$ & 15.20 & 2 & Pimephales promelas & Fish & ECOTOX & 23805 \\
\hline $\mathrm{LC}_{50}$ & 15.30 & 4 & Pimephales promelas & Fish & ECOTOX & 102597 \\
\hline $\mathrm{LC}_{50}$ & 14.73 & 4 & Brachydanio rerio & Fish & This study & \\
\hline
\end{tabular}




\section{Discussion}

\subsection{Assessment of the PNEC Values by AF and SSD}

AF and SSD were employed in the present study to induce the PNEC. The values from SSD are 1-2 orders of magnitude higher than those from the AF method. To obtain reasonable results, at least 8 data (from different species or different tests) are needed for the SSD method, as shown in Tables 1 and 2, there are 22 acute data from 8 species for BP, and 13 acute data from 9 species for DEET. Although the data of BP or DEET are more than 8 , the data diversity and numbers were not enough for providing reasonable and trustworthy results, so the deduced value by SSD may underestimate the PNEC values. Therefore, the PNEC values deduced from the AF method are recommended and applied in the discussion for assessing the ecological risk of BP and DEET. We do not deny that, when the value from the AF method is applied as a reference to make criteria for protecting ecosystem, it may overestimate. However, from the point of protecting the ecosystem at the greatest extent, the PNEC value deduced by the AF method is more reasonable when there is no perfect evaluation system at present.

In the present study, the PNEC values of both chemicals were deduced by with and without the present data, respectively, the results show different characteristics. For BP, the PNEC values deduced by the AF method are the same values with or without the present data, while the results by the SSD method are a little different: $0.480 \mathrm{mg} / \mathrm{L}$ with present data and $0.443 \mathrm{mg} / \mathrm{L}$ without present data, respectively. For DEET, the PNEC values deduced by the AF method are 0.407 and 0.712 with and without the present data, respectively. The results by the SSD method are $8.494 \mathrm{mg} / \mathrm{L}$ with present data, but $10.00 \mathrm{mg} / \mathrm{L}$ without present data. Although it could not be concluded that these results increased or decreased the PNEC values, it is definitely that the present study enriched the database for the ecological assessment of the two chemicals and further improved the rationality of the assessment conclusion, for the principle of the assessment method is: the more data you provide, the more refined your assessment will be.

\subsection{The Acute Toxicity and Ecological Risk of BP}

According to the acute toxicity results of $\mathrm{BP}$, the $96-\mathrm{h} \mathrm{EC}_{50}$ for C. vulgaris was $6.86 \mathrm{mg} / \mathrm{L}$, and the $24-\mathrm{LC}_{50}$ for D. magna was $7.63 \mathrm{mg} / \mathrm{L}$. Both were judged as high-level toxicity. The $96-\mathrm{h} \mathrm{LC}_{50}$ for B. rerio was $14.73 \mathrm{mg} / \mathrm{L}$, which was judged as medium-level toxicity. The sensitivity of C. vulgaris was higher than that of D. magna and B. rerio. To our knowledge, the present study is the first time to use C. vulgaris and B. rerio as organisms to test the acute toxicity of BP. The results provide new species and data for evaluation of the toxicity of BP.

Among all the acute toxicity data of BP registered in AIST-MeRAM, the 72-h EC 50 of Pseudokirchneriella subcapitata (algae) was $3.50 \mathrm{mg} / \mathrm{L}$, which was more sensitive than C. vulgaris in the present study. There were 4 data about the $\mathrm{LC}_{50}$ of $D$. magna; one was lower than $1.00 \mathrm{mg} / \mathrm{L}$, the last three were all from 1.00 to $10.00 \mathrm{mg} / \mathrm{L}(7.60 \mathrm{mg} / \mathrm{L}, 10.00 \mathrm{mg} / \mathrm{L}$, and $7.63 \mathrm{mg} / \mathrm{L})$, which were similar to the present results. The $96-\mathrm{h} \mathrm{LC}_{50}$ of Oryzias latipes (fish) was $10.00 \mathrm{mg} / \mathrm{L}$, which is a little lower than the results in the present study. There were 10 data about the $\mathrm{LC}_{50}$ of Pimephales promelas (fish), 9 of which were between 14.20 and $15.30 \mathrm{mg} / \mathrm{L}$, which is very close to the $96-\mathrm{h} \mathrm{LC}_{50}$ value $(14.73 \mathrm{mg} / \mathrm{L})$ of $B$. rerio in the present study. These results indicated that the $96-\mathrm{h} \mathrm{LC}_{50}$ of BP tested by $B$. rerio was reasonable as compared with the results obtained by other species of fish. For the different trophic levels of biota exposed to BP, the sensitivities were different. Algae were more sensitive than fish. Algae are primary producers in the aquatic trophic web, the harmful effect on algae may affect the stability and function of the ecosystem, so the ecological risk of BP should be fully realized.

According to the assessment results by the AF method, the PNEC value of BP was $0.003 \mathrm{mg} / \mathrm{L}$. It has been reported that the concentration detected in the Zhujiang River in China are 0.10-5.30 ng/L [17], and this value is much lower than the PNEC value. Similarly, the concentrations of the most commonly used UV filters, 4-MBC, BP-3, BP-4, and EHMC measured in coastal seawater samples from Spain ranged between 35 and $164 \mathrm{ng} / \mathrm{L}$ [18]. These facts indicated that BP could still 
be considered as a low environmental risk chemical at present. However, BPs have been detected in urine samples from individuals in the United States and China [3]. Concentrations of BP-3 (one of the derivatives of BP) have been measured at $9.97 \mathrm{mg} / \mathrm{L}$ in children and $15.7 \mathrm{mg} / \mathrm{L}$ in adults in United States; in China, the concentration of $0.62 \mathrm{mg} / \mathrm{L}$ in children and $0.98 \mathrm{mg} / \mathrm{L}$ in adults have been recorded. In Europe, concentrations of 4-MBC (4-methylbenzylidene camphor) and OC (octocrylene), two widely used UV filters, were determined in the muscle tissue of fish (brown trout, Salmo trutta fario) from seven small Swiss rivers, which all receiving inputs from wastewater treatment plants [19]. These indicated that the chemicals were transported into human and wild organism bodies through ecological processes and may have a potential health risk. BP has been proved as a type of endocrine disrupter, when it reaches an effective concentration, may cause damage to human health. However, the path of acquisition and how it affects the biota in the ecosystem still remain unknown.

The results in the present study provided most recent ecotoxicological research for the BP. The acute toxic effects on tree typical organisms in the aquatic ecosystem were tested; further, the PNEC were deduced to evaluate the risk to environment. The results can provide references for environmental criteria. Because BPs are widely used in many personal care products in our everyday life, its potential hazard to aquatic organisms and to humans should be further studied.

\subsection{The Acute Toxicity and Ecological Risk of DEET}

In the acute toxicity results of DEET, the $96-\mathrm{h} \mathrm{EC}_{50}$ to $C$. vulgaris was $270.72 \mathrm{mg} / \mathrm{L}$, the $24-\mathrm{h} \mathrm{LC}_{50}$ to $D$. magna was $40.74 \mathrm{mg} / \mathrm{L}$, and the $96-\mathrm{hCC}_{50}$ to $B$. rerio was $109.67 \mathrm{mg} / \mathrm{L}$. The acute toxicity of $D$. magna was judged as medium-level toxicity, while the acute toxicity of $C$. vulgaris and B. rerio were judged as low-level toxicity. The sensitivity of D. magna was higher than that of $C$. vulgaris and B. rerio. To our knowledge, this is the first time to use $C$. vulgaris and B. rerio to test the acute toxicity of DEET. The results provided new data for the ecotoxicological assessment of DEET.

Among all the data registered in the AIST-MeRAM about the acute toxicity of DEET, the 72-h EC 50 to Pseudokirchneriella subcapitata (algae) was $100.00 \mathrm{mg} / \mathrm{L}$, which was more sensitive than $96-\mathrm{h} \mathrm{EC}_{50}$ of C. vulgaris. There were three data of the acute toxicity of DEET to D. magna: $75.00 \mathrm{mg} / \mathrm{L}, 74.00 \mathrm{mg} / \mathrm{L}$, and $40.74 \mathrm{mg} / \mathrm{L}$. The present result $(40.74 \mathrm{mg} / \mathrm{L})$ is similar with these former studies, which indicated the rationality of the present result. There were two data of the $\mathrm{LC}_{50}$ of DEET to Pimephales promelas (fish) — both are $110.00 \mathrm{mg} / \mathrm{L}$ - and two data about the $\mathrm{LC}_{50}$ of DEET to Gambusia affinis (fish) - both are $235.00 \mathrm{mg} / \mathrm{L}$. For Oncorhynchus mykiss (fish), the $\mathrm{LC}_{50}$ were 71.25 and $75.00 \mathrm{mg} / \mathrm{L}$, respectively. There was only one $\mathrm{LC}_{50}$ of DEET to Oryzias latipes (fish) at $100.00 \mathrm{mg} / \mathrm{L}$. The $96-\mathrm{h} \mathrm{LC} 50$ of B. rerio in this study is very close to all of the data reported on fish. According to the results for DEET described above, the sensitivity order is Oncorhynchus mykiss $>$ Daphnia magna $>$ Oryzias latipes $=$ Pseudokirchneriella subcapitata $>$ Pimephales promelas $>$ Gambusia affinis $>$ Chlorella vulgaris. Overall, the sensitivity of daphnids and fish was higher than that of algae. This can be explained that DEET is used as an insect repellent and there were corresponding target mechanisms in daphnids and fish.

The value of PNEC deduced by using the AF method is $0.407 \mathrm{mg} / \mathrm{L}$. In the published papers, the concentrations of DEET detected in the aquatic environment ranged from 0.60 to $1.20 \mathrm{ug} / \mathrm{L}$ [20], which is lower than the PNEC value. Therefore, at present, DEET could be classified as chemicals having low toxicity and risk to the environment. To our knowledge, there are no reports about DEET in the human body; however, as DEET is used as repellents in some perfume, the human body cannot avoid being exposed to DEET. Furthermore, as a widely used ingredient in PCPs, it can be discharged to the aquatic environment so that they can reach humans directly or indirectly by processes of enrichment, accumulation, and amplification through the food web. The study of the acute toxicity of DEET can provide a scientific basis for criteria and thus for management of the exposure concentration and the discharge standard.

\subsection{The Assessment of the Mixing Toxicity of BP and DEET}

The mixture toxicity of BP and DEET on C. vulgaris, D. magna, and B. rerio in the present study all showed an additive effect. The results explained these two chemicals' behavior in mixture conditions. 
Since BP and DEET have different structural compositions, their biological degradability pathways and degradation products may be different, so the interaction of the two chemicals afterwards in an actual environment may behave differently from the results in a laboratory. Therefore, the mixture of their degradation products may perform different interactions such as antagonism, additive effects, irrelevant effects, and synergy.

The results of the present study provided the acute toxic responses of three tropical organisms in the aquatic ecosystem to BP, DEET, and their mixture. The acute toxic data enriched the tested species and acute testing results for the database, thereafter increasing the rationality of the induced PNEC. The PNEC induced from this study evaluated the ecological risk of both chemicals. These will provide a theoretical basis for establishing water quality criteria.

In the future study, attention should be paid to the so-called lower risk, but may be potential disrupt chemicals. Further chronic toxic test and ecosystem level studies should also be carried to evaluate the physiological and developing effects on biota.

\section{Conclusions}

The acute toxic effects of BP and DEET on C. vulgaris, D. magna, and B. rerio were tested. The toxicity of BP to $C$. vulgaris and D. magna were judged as high-level toxicity, but that to B. rerio was judged as medium-level toxicity. For DEET, the acute toxicity of $C$. vulgaris and B. rerio were judged as low-level toxicity, and the acute toxicity of $D$. magna was judged as medium-level toxicity. The mixing toxicity of BP and DEET on C. vulgaris, D. magna, and B. rerio displayed an additive effect. The results explained the way of these two chemicals' behavior in mixture conditions. The risk assessment to the environment by the AF method concluded that both chemicals are a low risk to the environment at present. The results in the present study indicated the diversity and complexity of the toxic effect of $\mathrm{BP}$ and DEET in PCPs.

Since both BP and DEET are main components in personal care products, they are therefore high exposure sources to humans. BP has been identified as endocrine disruptors [8], and their potential high risk to ecosystems and human health over a long time period should be made widely known. The assessment of the acute toxicity of BP and DEET in the present study clarified the different toxic levels and different sensitivities from different tropical organisms in the aquatic ecosystem, and the results indicated the diversity and complexity of the toxic effect of chemicals in PCPs. Although the BP and DEET are evaluated as low-risk chemicals in the aquatic ecosystem, the identified characteristic as an endocrine disruptor [8] implied the high potential risk of the PCPs over a long time period.

Acknowledgments: The present study is supported by the National Scientific and Technology Major Project (2012ZX07101-005) and National Key Research and Development Program of China (2016YFB0601003-01). We thank Bin-Le Lin, at National Institute of Advanced Industrial Science and Technology, Japan, for providing advice on using the AIST-MeRAM and the manuscript.

Author Contributions: Li-Wei Sun, Yi-Min Zhang, and Hong-Qin Sun conceived and designed the experiments; Hong-Qin Sun, Yang Du, and Zi-Yang Zhang performed the experiment; Wen-Jing Jiang and Yan-Min Guo partly performed the experiments; Hong-Qin Sun and Li-Wei Sun analyzed the data; Xi-Wu Lu conceived part of the experiment and improved the manuscript; Yi-Min Zhang contributed analysis and preparation of the manuscript; Hong-Qin Sun and Li-Wei Sun wrote the paper.

Conflicts of Interest: The authors declare no conflict of interest.

\section{Abbreviations}

The following abbreviations are used in this manuscript:

BP benzophenone

DEET N,N-Diethyl-3-methylbenzamide

PCPs personal care products

PNEC predicted no-effect concentration 


\section{References}

1. Pedrouzo, M.; Borrull, F.; Marcé, R.M. Analytical methods for personal-care products in environmental waters. J. TrAC Trends Anal. Chem. 2011, 5, 749-760. [CrossRef]

2. Nakada, N.; Komori, K.; Suzuki, Y.; Konishi, C.; Tanaka, H.H. Occurrence of 70 pharmaceutical and personal care products in Tone River basin in Japan. J. Water Sci. Technol. 2007, 56, 133-140. [CrossRef] [PubMed]

3. Wang, L.; Kannan, K. Characteristic profiles of benzonphenone-3 and its derivatives in urine of children and adults from the United States and China. J. Environ. Sci. Technol. 2013, 21, 12532-12538. [CrossRef] [PubMed]

4. Liao, C.; Kannan, K. Widespread occurrence of benzophenone-type UV light filters in personal care products from China and the United States: An assessment of human exposure. J. Environ. Sci. Technol. 2014, 7, 4103-4109. [CrossRef] [PubMed]

5. Wang, Y.; Wu, H.; Wen, C.; Liu, G.H. Optimum Conditions of Improved MTT Assay for Estimating in Vitro Acute Cytotoxicity in Different Fish Cells. J. Environ. Sci. Technol. 2009, 5, 14-16.

6. Huang, W.; Mao, C.Q.; Cui, W. Research on Synthesis of Benzophenone. J. Shanghai Chem. Ind. 2008, 3, 4-6.

7. Balmer, M.E.; Buser, H.R.; Müller, M.D.; Poiger, T. Occurrence of some organic UV filters in wastewater, in surface waters, and in fish from Swiss lakes. J. Environ. Sci. Technol. 2005, 4, 953-962. [CrossRef]

8. Sun, Z.Z.; Ma, J.; Zhao, L.; Wang, L.B.; Yu, Y.H.; Hou, Y.J. Degradation of endocrine disruptor benzophenone in water by ozone-ceramic honeycomb. J. Nat. Sci. Heilongjiang Univ. 2006, 4, 428-432.

9. Li, M. Acute toxicity of benzophenone-type UV filters and paraben preservatives to freshwater planarian, Dugesia japonica. J. Toxicol. Environ. Chem. 2012, 3, 566-573. [CrossRef]

10. Sandstrom, M.W.; Kolpin, D.W.; Thurman, E.M.; Zaugg, S.D. Widespread detection of N,N-diethyl-mtoluamide in US Streams: Comparison with concentrations of pesticides, personal care products, and other organic wastewater compounds. J. Environ. Toxicol. Chem. 2005, 5, 1029-1034. [CrossRef]

11. Zenobio, J.E.; Sanchez, B.C.; Archuleta, L.C.; Sepulveda, M.S. Effects of triclocarban, N,N-diethyl-metatoluamide, and a mixture of pharmaceuticals and personal care products on fathead minnows (Pimephales promelas). J. Environ. Toxicol. Chem. 2014, 4, 910-919. [CrossRef] [PubMed]

12. Chemicals-Alga Growth Inhibition Test, GB/T 21805-2008, General Administration of Quality Supervision, Inspection and Quarantine, People's Republic of China; Standardization Administration of China. Available online: http:/ /www.sac.gov.cn/was5/web/search (accessed on 2 September 2016).

13. Method for Acute Toxicity Test of Daphnia Magna Straus, GB/T 16125-2012, Ministry of Health, People's Republic of China, Standardization Administration of China. Available online: http://www.sac.gov.cn/ was5/web/search (accessed on 2 September 2016).

14. Chemicals-Fish Acute Toxicity Test, GB/T 27861-2011. Administration of Quality Supervision, Inspection and Quarantine, People's Republic of China; Standardization Administration of China. Available online: http://www.sac.gov.cn/was5/web/search (accessed on 2 September 2016).

15. Wang, X.; Wei, F.; Qi, W. Monitoring Analysis Method of Water and Wastewater, 4th ed.; Ministry of Environmental Protection of the People's Republic of China: Beijing, China, 2013; pp. 767-781.

16. Hodges, G.; Roberts, D.W.; Marshall, S.J.; Dearden, J.C. Defining the toxic mode of action of ester sulphonates using the joint toxicity of mixtures. J. Chemosphere 2006, 1, 17-25. [CrossRef] [PubMed]

17. Bu, Q.W.; Wang, B.; Huang, J.; Deng, S.B.; Yu, G. Pharmaceuticals and personal care products in the aquatic environment in China: A review. J. Hazard. Mater. 2013, 262, 189-211. [CrossRef] [PubMed]

18. Paredes, E.; Perez, S.; Rodil, R.; Quintana, J.B.; Beiras, R. Ecotoxicological evaluation of four UV filters using marine organisms from different trophic levels Isochrysis galbana, Mytilus galloprovincialis, Paracentrotus lividus, and Siriella armata. J. Chemosphere 2014, 104, 44-50. [CrossRef] [PubMed]

19. Buser, H.R.; Balmer, M.; Schmid, P.; Kohler, M. Occurrence of UV filters 4-methylbenzylidene camphor and octocrylene in fish from various Swiss rivers with inputs from wastewater treatment plants. J. Environ. Sci. Technol. 2006, 40, 1427-1431. [CrossRef]

20. Sui, Q.; Huang, J.; Deng, S.B.; Fan, Q. Occurrence and removal of pharmaceuticals, caffeine and DEET in wastewater treatment plants of Beijing, China. J. Water Res. 2010, 2, 417-426. [CrossRef] [PubMed]

(C) 2016 by the authors; licensee MDPI, Basel, Switzerland. This article is an open access article distributed under the terms and conditions of the Creative Commons Attribution (CC-BY) license (http://creativecommons.org/licenses/by/4.0/). 